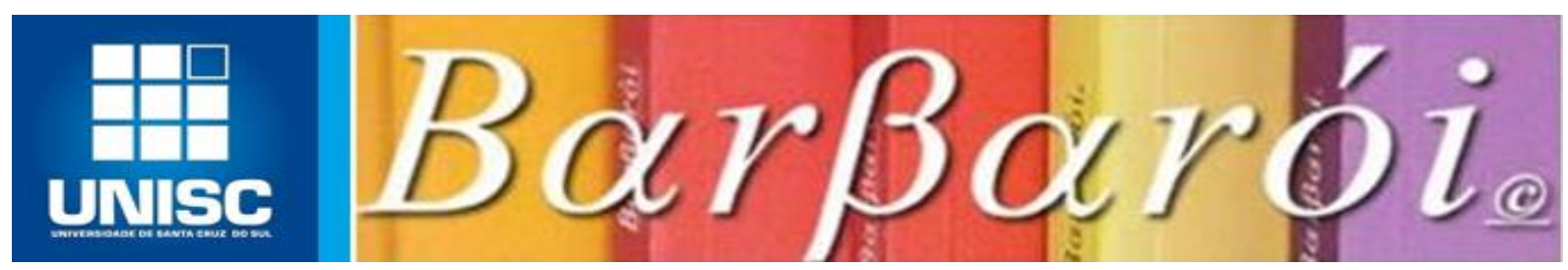

\title{
ASPECTOS DO TRABALHO E FORMAÇÃO DOCENTE NO SERVIÇO DE ATENDIMENTO EDUCACIONAL ESPECIALIZADO DA REDE ESTADUAL DE ENSINO DE SANTA CATARINA
}

\author{
DOI: http://dx.doi.org/10.17058/barbaroi.v0i0.9518

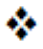 \\ Lediane Coutinho \\ Universidade da Região de Joinville - UNIVILLE - Brasil \\ Aliciene Fusca Machado Cordeiro \\ Universidade da Região de Joinville - UNIVILLE - Brasil
}

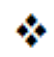

\section{Resumo}

Este trabalho tem por objetivo conhecer aspectos do trabalho e formação do professor do Serviço de Atendimento Educacional Especializado (SAEDE) na Rede Estadual de Ensino em Joinville/SC. Os procedimentos metodológicos envolveram a aplicação de questionários junto a dezesseis professoras atuantes no SAEDE em Joinville, sendo suas respostas analisadas por meio da Análise de Conteúdo (FRANCO, 2012). Os resultados evidenciaram que a formação continuada em serviço parece não ser favorecida nos espaços escolares em função das atuais condições de trabalho das docentes, que estão quase totalmente voltadas a atender estudantes. Entendeu-se que, para compreender aspectos do trabalho e formação dos professores do SAEDE é preciso conhecer e discutir a estrutura organizativa das escolas, bem como o contexto político, ideológico e econômico que as envolvem atuam como seus determinantes.

Palavras-chave: atendimento educacional especializado; trabalho docente; professor do SAEDE.

\section{Introdução}

O trabalho docente pode ser compreendido a partir de sua especificidade: $\mathrm{o}$ ato de ensinar, isto é, fazer alguém aprender algo (ROLDÃO, 1998). Tratando-se de um trabalho que, no Brasil do início do século XXI, se dá em um contexto capitalista e neoliberal, pode-se dizer que o trabalho docente se constitui de forma articulada a dimensões de ordens institucionais, políticas, econômicas, científicas e técnicas e, por se dar em uma sociedade dividida em classes, a atividade de ensinar é produzida dentro de contradições, conflitos, antagonismos e disputas (FRIGOTTO, 2006).

Para compreender o trabalho docente e sua especificidade no Serviço de Atendimento Educacional Especializado (SAEDE) da Rede Estadual de Ensino de Santa Catarina, é preciso, portanto, considerar essa ampla gama de forças que determinam o trabalho docente e ultrapassam o contexto da relação entre professor e estudante nos espaços escolares. 
Dentre essas forças determinantes do trabalho docente, estão os aspectos legais e políticos, na esteira dos quais figuram as reformas educacionais que, no Brasil, compreenderam "[...] a inclusão das pessoas com deficiência nas escolas regulares, e, com isso, a necessidade de sua reorganização para receber e atender a esses estudantes" (BERNARDES, 2014, p. 30). A mesma autora cita que tal reorganização atingiu de forma significativa o trabalho docente, que apesar de permanecer com a especificidade de ensinar algo a alguém, passou a fazê-lo com foco em um público distinto, hoje entendido como alvo da Educação Especial: estudantes com deficiência, transtornos globais do desenvolvimento e altas habilidades/superdotação (BRASIL, 2008).

Nesse contexto, o Atendimento Educacional Especializado (AEE) emergiu como “[...] novo e principal serviço apoiante aos estudantes considerados da Educação Especial que frequentam as escolas regulares e também aos profissionais que ali trabalham" (BERNARDES, 2014, p. 31). O referido atendimento, de acordo com a Política Nacional de Educação Especial na Perspectiva da Educação Inclusiva (BRASIL, 2008) possui um caráter suplementar e/ou complementar à escolarização regular, e prevê a existência de professores atuantes nas Salas de Recursos Multifuncionais (SRM), que são o local preferencial de realização dos atendimentos aos estudantes público-alvo da Educação Especial pelos referidos docentes.

Apesar de o trabalho docente abarcar todos os envolvidos no processo de escolarização nas escolas ou em instituições educacionais (OLIVEIRA, 2010), é notória a ênfase imputada sobre o professor no art. 9 da Resolução CNE/CEB n ${ }^{\circ}$ 4/2009, que institui Diretrizes Operacionais para o Atendimento Educacional Especializado na Educação Básica:

[...] a elaboração e a execução do plano de AEE são de competência dos professores que atuam na sala de recursos multifuncionais ou centros de AEE, em articulação com os demais professores do ensino regular, com a participação das famílias e em interface com os demais serviços setoriais da saúde, da assistência social, entre outros necessários ao atendimento. (BRASIL, 2009, p. 1, grifo nosso)

É possível observar, na redação supracitada, que compete aos docentes atuantes nas SRM ou em centros de AEE elaborar o plano de AEE e executá-lo. Os demais envolvidos citados não são explicitados como aqueles a quem compete a mesma função; aparecem, outrossim, como aqueles a quem o professor atuante nas SRM ou em centros de AEE deve estar articulado a fim de realizar o que é de sua competência: a elaboração e a execução do plano de AEE.

Ressalta-se, ainda, que não há menção ao papel de outros profissionais da escola na realização desta tarefa, como por exemplo, diretores escolares, coordenadores pedagógicos e 
supervisores escolares. Não se vê, também, referência a outras instâncias que sabidamente interpelam as escolas, como as Secretarias Municipais de Educação, as Gerências Regionais de Educação e o próprio Ministério da Educação. Torna-se evidente que sobre os ombros do professor está o peso de uma responsabilidade que não é só dele, mas que é entendida, ao menos nas diretrizes operacionais nacionais, como tal, favorecendo um processo de culpabilização individual dos professores enquanto outros atores, tão envolvidos na escolarização dos estudantes público-alvo da Educação Especial quanto eles, continuam no silenciamento de sua função nos documentos legais.

Debruçando-se, ainda, sobre a mesma Resolução, o art. 13 destaca quais são as atribuições do professor do AEE, elencando as seguintes:

I - identificar, elaborar, produzir e organizar serviços, recursos pedagógicos, de acessibilidade e estratégias considerando as necessidades específicas dos alunos público-alvo da Educação Especial;

II - elaborar e executar plano de Atendimento Educacional Especializado, avaliando a funcionalidade e a aplicabilidade dos recursos pedagógicos e de acessibilidade;

III - organizar o tipo e o número de atendimentos aos alunos na sala de recursos multifuncionais;

IV - acompanhar a funcionalidade e a aplicabilidade dos recursos pedagógicos e de acessibilidade na sala de aula comum do ensino regular, bem como em outros ambientes da escola;

$\mathrm{V}$ - estabelecer parcerias com as áreas intersetoriais na elaboração de estratégias e na disponibilização de recursos de acessibilidade;

VI - orientar professores e famílias sobre os recursos pedagógicos e de acessibilidade utilizados pelo aluno;

VII - ensinar e usar a tecnologia assistiva de forma a ampliar habilidades funcionais dos alunos, promovendo autonomia e participação;

VIII - estabelecer articulação com os professores da sala de aula comum, visando à disponibilização dos serviços, dos recursos pedagógicos e de acessibilidade e das estratégias que promovem a participação dos alunos nas atividades escolares. (BRASIL, 2009, p. 3)

O trabalho no Atendimento Educacional Especializado, portanto, incumbe ao professor uma série de funções que estão vinculadas a um saber-fazer específico com os estudantes público-alvo da Educação Especial. De acordo com Bernardes (2014, p. 29):

[...] esse saber-fazer indica a necessidade de possuir e desenvolver habilidades e conhecimentos diversificados, mas específicos, seja para o uso dos diversos recursos tecnológicos, de acessibilidade, seja para o trabalho de acompanhamento dos recursos pedagógicos junto aos estudantes e profissionais da escola.

As diretrizes, ao descreverem as atribuições do professor atuante no AEE, clarificam o que se espera de seu trabalho, mas omitem que, a fim de realizá-las, há uma série de condições concretas que se fazem necessárias. Ponderando a esse respeito, Oliveira (2010, p. 141) apontou algumas delas:

[...] estrutura e organização da escola, das condições de trabalho do professor e das possibilidades delineadas pelas políticas educacionais em toda sua plenitude. Além desses aspectos, há outro, muitas vezes desconsiderado nas proposições de formação e atuação docente: o sentimento do professor, a relação que estabelece com o seu 
trabalho e a forma como se apropria, no contato diário com seus alunos, da história e da existência de cada um deles.

Nessa perspectiva, os aspectos que compõem o trabalho docente dos professores no AEE, como as condições de trabalho e a formação, precisam ser considerados a fim de compreender as (im)possibilidades de realiza-lo junto aos estudantes, famílias, professores da sala de aula comum e demais profissionais da escola.

Aproximando-se, agora, da especificidade do trabalho docente no Serviço de Atendimento Educacional Especializado no contexto da Rede Estadual de Ensino de Santa Catarina, objeto desta investigação, salienta-se que no referido estado, foi em 1957 que se deu início, oficialmente, ao atendimento ao público na área de Educação Especial, no formato de classe especial para crianças com deficiência. Nos anos 1960, em parceria com a iniciativa privada, o governo do estado de Santa Catarina determinou o funcionamento dos serviços de educação especial e, mais tarde, em 1968, foi criada a Fundação Catarinense de Educação Especial (FCEE), uma instituição pública com o objetivo de definir as diretrizes necessárias ao funcionamento da Educação Especial em âmbito estadual, bem como promover a formação profissional e a realização de estudos neste campo. (SANTA CATARINA, 2006).

A partir da implementação da Política de Educação do Estado de Santa Catarina (SANTA CATARINA, 2006), instituiu-se o chamado SAEDE, Serviço de Atendimento Educacional Especializado, realizado preferencialmente de rede regular de ensino, “[...] atendendo a todas as peculiaridades educacionais das pessoas com deficiência, condutas típicas e altas habilidades" (SANTA CATARINA, 2006, p. 30).

De acordo com o Programa Pedagógico (SANTA CATARINA, 2009):

[...] o Serviço de Atendimento Educacional Especializado é uma atividade de caráter pedagógico, prestado por profissional da educação especial, voltado ao atendimento das especificidades dos alunos com deficiência, condutas típicas ou com altas habilidades, matriculados na rede regular de ensino (SANTA CATARINA, 2009, p. 25).

Percebe-se que o público-alvo do SAEDE abrange as "condutas típicas", que não são contempladas na Política Nacional de Educação Especial (BRASIL, 2008) com essa denominação. Essas condutas contêm os Transtornos Globais do Desenvolvimento (TGD), citados na política nacional, mas também englobam o Transtorno do Déficit da Atenção com Hiperatividade/Impulsividade (TDAH/I). Aí reside uma primeira distinção entre as políticas nacional e estadual: o que se entende por "público-alvo da Educação Especial”.

Ponderando que o objetivo deste estudo não é analisar propriamente as referenciadas políticas, mas sim conhecer aspectos do trabalho e formação do professor atuante no Serviço de Atendimento Educacional Especializado nas escolas da Rede Estadual de Ensino em 
Joinville - SC, compreende-se que a relevância de uma proposta de investigação como esta consiste em avançar no movimento de construção de conhecimento sobre um serviço que está em processo de constituição, visando a escolarização de todos ao mesmo tempo que se encontra enredado em uma trama social que, como aludiu Martins (1997), inclui para excluir.

No próximo tópico, será apresentado o percurso metodológico adotado no processo de construção da pesquisa, explicitando a abordagem, o processo de coleta de dados e o método utilizado para análise dos mesmos. Além disso, também será abrangida uma breve caracterização do perfil das professoras que participaram deste estudo.

\section{Percurso metodológico}

Pelo fato de se interessar pela compreensão das professoras do SAEDE acerca de aspectos de seu trabalho e formação, esta investigação possui uma abordagem qualitativa, que não centra sua preocupação na quantificação ou na representatividade numérica da realidade, mas se volta ao aprofundamento da compreensão e explicação de seus fenômenos, interessando-se pelos sentidos e significados atribuídos por aqueles que os vivenciam (SILVEIRA \& CÓRDOVA, 2009; SANTOS, 2016). De acordo com Gatti e André (2011, p. 29):

[...] assume-se, nesta perspectiva, que destes sentidos e significados é que se alimenta nosso conhecer e são eles que traduzem as mudanças dinâmicas no campo social, no campo educacional, cuja compreensão pode trazer uma aproximação do real mais condizente com as formas humanas de representar, pensar, agir, situar-se.

Considerando o objetivo de conhecer aspectos do trabalho e formação do professor do Serviço de Atendimento Educacional Especializado (SAEDE) nas escolas da Rede Estadual de Ensino de Santa Catarina, situadas no município de Joinville/SC, escolheu-se como instrumento para coleta de dados um questionário elaborado com 23 perguntas: 5 fechadas, 7 abertas e fechadas e 11 abertas. As questões foram organizadas em 2 eixos, sendo um pertinente à caracterização do perfil das docentes e outro focalizado em aspectos de seu trabalho e formação.

A aplicação do instrumento junto às participantes foi precedida pela aprovação do projeto de pesquisa junto ao Comitê de Ética em Pesquisa com Seres Humanos, bem como pelo alinhamento prévio com a Gerência Regional de Educação, à qual foi apresentada a proposta do estudo. Todas as docentes que optaram por participar da pesquisa o fizeram voluntariamente, por meio da assinatura de um Termo de Consentimento Livre e Esclarecido.

Ao todo, das 40 escolas que compõe a Rede Estadual de Ensino no município de Joinville e atendem 27.409 estudantes do primeiro ano do ensino fundamental até o terceiro 
ano do ensino médio (dados de 2015), foram visitadas 21, pelo fato de contarem com a estrutura das Salas de Recursos Multifuncionais para realização do SAEDE. Conforme dados da Gerência Regional de Educação, à época do estudo, em 2015, o referido serviço atendia 194 crianças matriculadas em turmas do ensino fundamental ao ensino médio.

Considerando que, nas 21 escolas visitadas, houve dois casos de uma mesma professora atuar em duas escolas diferentes, o número de professoras convidadas a participar voluntariamente da pesquisa foi de 19. Destas, 16 responderam ao questionário e passaram a constituir as participantes deste estudo. Caracterizando-as brevemente, inicia-se destacando que as professoras participantes da pesquisa, em sua totalidade, são do gênero feminino. Bernardes (2014) e Santos (2016), que investigaram professoras da Rede Municipal de Ensino no mesmo município aqui estudado, também obtiveram o mesmo dado: uma amostra 100\% feminina, o que permite reiterar a necessidade de continuar a discutir questões de gênero no âmbito da profissão docente, uma vez que foi possível identificar a perpetuação de "[...] um processo de construção ideológica, no qual foram relegados à mulher alguns espaços públicos, entre os quais se destacam [...] a docência no ensino elementar" (TAMBARA, 1998, p. 39).

Por meio do ano de nascimento informado no questionário, constatou-se que a idade das professoras se situa entre 25 e 58 anos. Em relação ao tempo de atuação na docência, há variação entre 2 e 20 anos, sendo que a maioria (11 professoras) atua há 6 anos ou mais na docência em sala comum, o que pode sugerir que as docentes atuantes no SAEDE possuem um repertório significativo de experiências como professoras no ensino regular.

Já no que tange ao tempo de atuação no SAEDE, quase metade (7 docentes) das participantes do estudo trabalham neste serviço há 1 ano, enquanto as demais variam de 2 a 10 anos. Esse dado corrobora com outra constatação que chamou a atenção: 14 das 16 professoras que participaram do estudo são admitidas em caráter temporário (ACT). Sobre esse aspecto, ainda que a Lei Complementar $n^{\circ} 456$ (SANTA CATARINA, 2009b) ampare esse processo de admissão de profissionais por prazo determinado para atuação do magistério público estadual, para atender à necessidade temporária de interesse público, pode-se destacar que "[...] apesar dos contratos garantirem os mesmos componentes de remuneração dos profissionais efetivos, os trabalhadores não ingressam e não têm acesso à movimentação na carreira, o que agrava o quadro de desvalorização e precarização" (ARAÚJO, 2015, p. 137).

Ainda com relação à caracterização das 16 participantes da pesquisa, no tocante à carga horária de trabalho no SAEDE, a maioria (10 docentes) relatou trabalhar 40 horas semanais. Quanto às demais, 5 mencionaram que atuam por 20 horas semanais e 1 informou que sua jornada de trabalho no SAEDE supera as 40 horas semanais, o que pode gerar 
questionamentos sobre as condições do trabalho docente em que essas professoras estão enredadas, uma vez que a jornada de 40 horas por semana ou mais pode sugerir indícios de intensificação do trabalho docente no SAEDE.

Após breve caracterização do perfil das professoras que participaram desde estudo, segue-se com a descrição do percurso metodológico, focalizando agora o processo de análise dos dados. Suas respostas foram analisadas com base em pressupostos da Análise de Conteúdo (FRANCO, 2012), que se debruça sobre os dados entendendo-os como mensagens, que podem ter seu conteúdo analisado por meio de indicadores como recorrência, contradição e complementaridade. Percebe-se que o esforço analítico do pesquisador no contato com os dados de pesquisa situa a Análise de Conteúdo em um âmbito de pesquisa que "[...] reconhece o papel ativo do sujeito na produção de conhecimento" (FRANCO, 2012, p. 10).

\section{Aspectos do trabalho e formação docente no SAEDE}

Inicia-se a discussão de alguns aspectos da formação das professoras que trabalham no SAEDE da Rede Estadual de Ensino no município de Joinville a partir do tópico "formação inicial". Sobre este aspecto, identificou-se que 15 das 16 participantes são graduadas em Pedagogia, e apenas uma têm formação específica em Educação Especial. Também 15 das 16 professoras informaram que se encontram em processo de formação continuada, pelo fato de estarem realizando curso de especialização. Destas 15,8 professoras estão cursando a especialização em Inclusão Escolar, 6 em Psicopedagogia e uma em Práticas Pedagógicas.

De acordo com o Programa Pedagógico da Fundação Catarinense de Educação Especial (SANTA CATARINA, 2009a), a formação inicial do professor atuante no SAEDE pode ser tanto em nível superior quanto em nível médio. No município pesquisado observouse que, mesmo havendo essa possibilidade de ter a formação em nível médio, todas as professoras que participaram da pesquisa realizaram a formação em nível superior e a maioria deu continuidade aos estudos em cursos de pós-graduação. No entanto, concorda-se com Michels (2004) quando aponta que o referido Programa Pedagógico, ao admitir que a formação inicial pode ser realizada tanto em nível médio quanto superior, reforça que esta ocorra no nível mais baixo.

Em relação ao processo de ingresso no SAEDE, um dado que pode ser salientado é que todas as professoras pesquisadas iniciaram como docentes na educação pública trabalhando em salas de aulas regulares, e só posteriormente se inseriram no SAEDE, visto que não há concurso para público específico para esta função. Os professores que a exercem são selecionados e admitidos a caráter temporário ou são concursados para outra função e 
remanejados para atuar provisoriamente nesse serviço. De modo geral, a inserção profissional no SAEDE ocorreu por escolha das próprias professoras, por identificação com o trabalho junto a estudantes público-alvo da Educação Especial no ensino comum, conforme sinalizado por algumas docentes quando questionadas sobre como se deu sua inserção no SAEDE: Por já ter exercido a função no município sendo professora de autista, TDH, TDG,
TDI e deficiência visual e auditiva me inscrevi para a vaga de professora do SAEDE
e logo fui chamada. (P.1)

De início trabalhava como segunda professora bilíngue, interprete e instrutora de Libras, em escolas estaduais desde final de 2013. Fiz a inscrição para o processo seletivo e no início de 2015 fiz a escolha de vaga. (P.6)

Sempre trabalhei com educação especial, em 2011 tive a oportunidade de trabalhar no AEE em Jaraguá do Sul e me apaixonei ainda mais. Quando voltei para Joinville vim focada em trabalhar no SAEDE. Montei o processo na escola e abrimos a sala do SAEDE. (P.12)

Suas respostas permitem destacar o papel da interação com estudantes público-alvo da Educação Especial e da experiência prévia de ensinar o referido alunado ao longo da trajetória docente, na posterior escolha de atuar no Serviço de Atendimento Educacional Especializado. Santos (2016), ao investigar o processo de se tornar professora do Atendimento Educacional Especializado, e chegou à compreensão de que, em alguns casos, a experiência de ensinar alunos público-alvo no ensino comum pode ser entendida como um marco importante no processo de identificação com a Educação Especial e na opção subsequente por atuar no Atendimento Educacional Especializado. No entanto, a autora adverte que:

[...] a interação com pessoas com deficiência não é determinante para a identificação com o trabalho docente no Atendimento Educacional Especializado ou mesmo para o desenvolvimento de atitudes inclusivas. O que se pode afirmar é que ao apropriarem-se dessas relações, pode-se construir sentidos acerca da diferença, da deficiência e da aprendizagem de alunos considerados como público-alvo da Educação Especial. Cada pessoa fará das relações com esse outro uma significação própria, terá uma vivência única, que será constituída não somente a partir do que se viveu em sala de aula, mas fora dela - na relação com a família, com a comunidade, em determinadas condições econômicas e sociais. (SANTOS, 2016, p. 89)

Aproximando-se, agora, de aspectos do trabalho docente no SAEDE, buscou-se no Programa Pedagógico da Fundação Catarinense de Educação Especial uma elucidação acerca de quais seriam as atribuições fundamentais a serem cumpridas por essas docentes. Conforme o referido documento, cabe às professoras do SAEDE:

\footnotetext{
» promover, sistematicamente, junto à equipe técnica, pedagógica e administrativa da unidade escolar, repasses técnicos referentes ao atendimento;

» orientar e subsidiar o professor de sala de aula (ensino regular) e a turma na qual o aluno está matriculado;

» propor intervenções pedagógicas, em sala de aula, que possibilitem a efetiva participação dos educandos no ensino regular;
} 
» elaborar e executar planejamento de atividades, conforme as especificidades dos alunos;

» solicitar a colaboração do Integrador de Educação Especial e Diversidade, quando necessário, para a elaboração do planejamento de atividades pedagógicas, relatórios, cronograma de orientação para o ensino regular, avaliações e outras orientações que se fizerem necessárias;

» registrar as assessorias para rede regular, utilizando a ficha de presença, solicitando sempre a assinatura do diretor e professor da escola orientada, bem como todas as orientações dadas à escola e à família;

» informar a equipe técnica e administrativa da escola do ensino regular quanto às características do Serviço e as peculiaridades dos educandos atendidos no SAEDE;

» participar de reuniões e conselhos de classes na unidade escolar onde o aluno está matriculado;

» promover palestras, encontros com professores, funcionários, alunos, pais;

» participar da elaboração do projeto político-pedagógico;

» orientar o professor da classe regular quanto às adaptações curriculares no contexto da metodologia, avaliação e temporalidade;

» participar de reuniões mensais com o Integrador de Educação Especial e Diversidade para estudo e orientação técnica referente ao trabalho realizado em SAEDE;

» zelar pela conservação do espaço físico, dos equipamentos e materiais pedagógicos específicos do SAEDE;

» solicitar, por escrito, ao Integrador de Educação Especial e Diversidade, assessoria técnica em educação especial, material específico para as atividades pedagógicas, reavaliação diagnósticas periódicas e outras orientações. (SANTA CATARINA, 2009a, p. 28-29)

Listar essas atribuições, no entanto, nem sempre deixa claro o fato de que são imensos os desafios que acompanham as docentes do SAEDE em seu trabalho. A ação pedagógica que lhes é demandada implica a complexa tarefa de realizar, nos espaços escolares, uma forma de educação que contemple a diversidade, buscando assegurar aos alunos público-alvo da Educação Especial não somente a socialização com os demais alunos, mas especialmente uma aprendizagem escolarizada significativa. Os desafios se ampliam quando analisados sob a ótica de que essa tarefa se situa "[...] na contracorrente das condições objetivas de um modo de organização escolar pautado em um modelo capitalista e tecnológico, sustentado por relações de exclusão" (RENGEL, CORDEIRO \& STEINER, 2015, p. 1358), que localiza o trabalho deste professor em um contexto, por vezes, excludente.

Ainda que haja uma lista de atribuições estabelecidas no Programa Pedagógico (SANTA CATARINA, 2009a), é sabido que documentos como este não são tomados como algo definitivo por aqueles envolvidos no processo de escolarização. Como explicitou Michels (2004, p. 44):

[...] por mais que as legislações e as normas instituídas conformem práticas, estas serão apreendidas por sujeitos que darão vida a estes encaminhamentos políticos. Os sujeitos envolvidos entendem as indicações políticas de maneira distinta, conforme suas vivências, seus interesses, sua organização profissional, entre outros. Cada instituição educacional acaba por "implementar" as políticas à sua maneira. 
Desse modo, perguntou-se às professoras participantes deste estudo quais eram os principais desafios por elas vivenciados no trabalho, ao que responderam:

Buscar a autonomia dos alunos; elaboração conceitual; orientação para pais $e$ professores. (P.4)

Inclusão do segundo professor na escola, empoderamento do aluno de inclusão. Criação de jogos e brincadeiras e arte terapia. (P.16)

A maior recorrência de desafios sinalizados pelas professoras do SAEDE encontra-se no "conhecimento especializado", conforme ilustram as falas a seguir:

Primeiramente o conhecimento, pois muitas vezes nos deparamos com conhecimentos específicos que nem sempre temos domínio. (P2)

Trabalhar com várias deficiências o qual nos leva a pesquisar e a estudar todos os dias, isso nos traz um grande conhecimento e crescimento profissional. (P3)

O momento em que recebemos um aluno com uma "doença" grave (temos caso na escola), com alguma deficiência, síndrome ou transtorno, os quais não temos domínio da situação ou conhecimento para trabalharmos, é desafiados buscarmos este conhecimento por conta própria. (P6)

É possível notar que o desafio vivenciado pelas professoras na busca por "conhecimento especializado" é revelador de um foco na deficiência do estudante, e não no processo de escolarização como um todo. Pode-se inferir, nesse sentido, que o "conhecimento especializado" buscado pelas docentes estaria mais relacionado a saberes médicos e/ou psicológicos, do que a saberes pedagógicos, evidenciando que uma perspectiva médicopsicológica parece ainda persistir nas concepções e práticas docentes na Educação Especial.

Essa perspectiva, cujas raízes históricas remontam ao período colonial brasileiro (1500-1822), é balizada por saberes médicos e psicológicos, que tentavam “[...] explicar o não aprender, centrado nos distúrbios orgânicos, nas disfunções das crianças das mais variadas naturezas" (SOUZA, 2008, p. 2). Assim, passou-se a direcionar o foco da não-aprendizagem ao indivíduo e sua estrutura/funcionamento biopsicológico, deixando de considerar como ponto central do processo de escolarização o complexo universo de questões institucionais, políticas, individuais, estruturais e funcionais que estão presentes no cotidiano escolar (SOUZA, 2008).

Observando o modo como as professoras compreendem os desafios de seu trabalho e sabendo das atribuições que compõem sua função segundo o Programa Pedagógico (SANTA CATARINA, 2009a), pode-se compreender que uma formação continuada teoricamente consistente é, de fato, um aspecto importante para que o professor tenha condições de ensinar os estudantes público-alvo da Educação Especial, com atenção às estratégias de ensino 
diferenciadas que podem se fazer necessárias conforme a singularidade de suas necessidades educativas.

Isto porque se entende que essa formação pode constituir uma maneira de conhecer mais sobre o processo de escolarização e as condições objetivas que o constituem, oportunizando o desenvolvimento de uma postura crítica frente ao trabalho docente. Sabe-se, contudo, como já exposto, que o trabalho docente não depende apenas do professor e seus saberes, pois é interpelado por questões estruturais e organizativas da escola e está imbricado a questões políticas, institucionais, econômicas, ideológicas, sociais e culturais.

Entretanto, 10 das 16 professoras pesquisadas destacam que suas cargas horárias de trabalho compostas por 40 horas semanais são intensas, o que de certo modo dificulta a realização de processos de formação continuada e/ou em serviço, uma vez que as condições de trabalho dessas professoras aponta para indícios de intensificação do trabalho docente no SAEDE, que por meio de suas falas, aparece como um trabalho muito mais voltado ao volume de atendimentos aos estudantes do que a outros aspectos, como planejamentos, trocas de experiências e estudos.

Esses dados fazem refletir sobre o papel das condições de trabalho na atividade docente, uma vez que, como ressaltaram Hypolito, Vieira e Pizzi (2009, p. 109):

[...] nos moldes mais gerencialistas, que temos vivenciado mais recentemente, os processos de intensificação [do trabalho docente] tendem a apresentar maior distanciamento do conceito clássico ${ }^{1}$, e podem aparentemente ter maior tempo de preparo fora da sala de aula, maior possibilidade de práticas curriculares mais criativas, condições de trabalho organizadas a partir de modos de gestão mais abertos [...]. Muitas das atividades e tarefas propostas, boa parte realizadas fora das escolas, aparecem como inovações e podem aparentar um caráter mais criativo e insinuarem um trabalho pedagógico mais reflexivo. Contudo, o que podemos estar vivenciando são evidências cada vez maiores de um processo de auto-intensificação do trabalho docente.

Logo, para exercer plenamente o trabalho docente no SAEDE, condições de trabalho que prevejam de forma sistematizada um processo de formação contínua não apenas dos professores, mas de todos os envolvidos no processo de escolarização dos estudantes públicoalvo da Educação Especial, afirmam-se como contributivas ao desenvolvimento de estratégias de ensino adequadas às diferentes necessidades educativas. Como sinalizado por Haddad e Silva (2012, p. 6):

\footnotetext{
${ }^{1}$ Este "conceito clássico" do processo de intensificação do trabalho docente a que se referem os autores pode ser compreendido como aquele em que um trabalho docente intensificado remete a um "[...] aumento de trabalho em sala de aula, práticas menos criativas, muitas tarefas realizadas fora da escola e piores condições de trabalho" (HYPOLITO, VIEIRA \& PIZZI, 2009, p. 109)
} 
[...] a hora atividade como espaço de formação continuada e de discussão coletiva dos problemas pedagógicos pode promover a superação das formas alienadas do pensamento através das leituras e estudos numa perspectiva crítica, promovendo a tomada de consciência do professor sobre seu trabalho e, consequentemente, o resgate do sentido numa perspectiva de formação humana.

Este processo de formação, no entanto, precisa estar atrelado ao modo como as professoras do SAEDE experimentam seu trabalho e as condições em que este é realizado. Arroyo (2007) chama a atenção para o fato de que a condição e o trabalho docente continuam segmentados em áreas, disciplinas, remuneração, carreira e prestígio, e essa segmentação culmina em diferentes maneiras do professor perceber seu trabalho. Atentar à estrutura organizativa do trabalho docente e às autoimagens do professor são aspectos importantes para se pensar processos e políticas de formação, uma vez que “[...] a formação dos professores é indicada, ao menos discursivamente, como uma das estratégias mais eficazes contra a falta ou a má qualidade da educação no país" (MICHELS, 2015, p. 142).

Se a formação continuada, enquanto prática organizada pelos sistemas de ensino tem seu papel reconhecido na qualificação do trabalho docente pela produção científica, mas nem sempre são ofertadas pelas escolas e vivenciadas no cotidiano profissional pelas professoras, optou-se por investigar se as docentes recorriam a outras fontes de aprendizagem no intuito de refletir sobre suas práticas e buscar estratégias adequadas ao ensino especializado. Quando questionadas sobre quais fontes são as mais utilizadas por elas, destacaram-se em seus relatos as trocas de experiências com os demais profissionais da escola, bem como o uso da Internet (acesso a artigos, sites, materiais fornecidos pelo MEC, etc.):

Além das experiências já vividas, busco auxílio nos sites, livros e principalmente aos profissionais que já atendem as crianças em outras instituições. (PI)

Busca-se através de pesquisas realizadas pela Fundação [Fundação Catarinense de Educação Especial] em materiais específicos como o caso de TDAH. As coleções disponíveis pelo MEC, cursos oferecidos pela GERED, internet, e trocas de experiências com colegas de outros SAEDE. (P2)

Cursos, encontros quinzenais com outras profissionais da área, livros e pesquisas através da internet. (P11)

Algumas professoras relatam que essas trocas de experiências sobre suas práticas educativas contribuem muito na formação docente, no âmbito de suas reflexões acerca do processo pedagógico e na visão de Educação como um todo:

Sempre há trocas de informações e experiências com relação a mudanças de hábitos elou desvios de comportamentos na sala dos alunos que frequentam o SAEDE. Isso ajuda com novas estratégias para auxiliar o trabalho e formação dos professores, (...). Esta parceria também acontece com os segundos professores. (P6) 
Trabalho em conjunto com o segundo professor, propondo atividades e adaptações para melhorar a qualidade do processo de ensino para os alunos da educação especial. (P11)

A valorização das trocas de experiências por parte das professoras enseja uma reflexão sobre o fato de que, nem sempre, as práticas e reflexões docentes podem ser valiosas ou acertadas, uma vez que, por exemplo, docentes iniciantes tendem a agir conforme modelos tradicionais e exemplos caricatos da docência (GARCIA, HYPOLITO \& VIEIRA, 2005). Além disso, os mesmos autores também pontuaram que:

[...] o discurso do saber docente como reflexão prática, ao superestimar o cotidiano docente e sobrevalorizar o saber experiencial, pode distanciar os professores e as professoras daqueles objetivos sociais e morais mais amplos que acabam sendo definidos exclusivamente pelas políticas educacionais e governamentais. (GARCIA, HYPOLITO \& VIEIRA, 2005, p. 51)

Também chamou a atenção nos relatos das professoras supracitados a referência feita pelas docentes à parceria com o segundo professor ${ }^{2}$, atuante na sala de aula regular. Esse destaque ao trabalho em conjunto entre professor do SAEDE e segundo professor pode indicar, além de uma possível parceria, uma perpetuação de um modelo de educação fundamentado no paradigma da segregação, no qual o estudante público-alvo da Educação Especial está na escola e na sala de aula regular, porém seu processo de aprendizagem se dá de forma separada dos demais. Esse caráter ilusório da inclusão implica no que se chama de inclusão perversa, na qual a sociedade exclui para incluir (SAWAIA, 2012). Contextualizando tal perversidade no âmbito econômico e social, a autora explica que:

[...] todos estamos inseridos de algum modo, nem sempre decente e digno, no circuito reprodutivo das atividades econômicas, sendo a grande maioria da humanidade inserida através da insuficiência e das privações, que se desdobram para fora do econômico [...]. Dessa forma, a exclusão passa a ser entendida como descompromisso político com o sofrimento do outro. (SAWAIA, 2012, p. 8)

Perceber esses tensionamentos implica reconhecer, como fez Paulo Freire (2013), que a educação é ideológica, e a forma sutil com que os discursos sobre inclusão são revestidos ideologicamente esconde, por vezes, uma forma de educação que persiste em um modelo que segrega, separa os estudantes público-alvo da Educação Especial dos demais, mesmo que estejam na mesma sala. Paulo Freire (2013, p. 129) advertiu que "o discurso ideológico nos ameaça de anestesiar a mente, de confundir a curiosidade, de distorcer a percepção dos fatos, das coisas, dos acontecimentos".

${ }^{2}$ O segundo professor de turma, instituído pela Rede Estadual de Ensino de Santa Catarina, trata-se de um profissional atuante nas escolas da rede regular de ensino em que haja matrículas de estudantes público-alvo da Educação Especial. Sua função é atuar como "[...] corregente nas turmas de séries iniciais do ensino fundamental e colaborador do professor nas séries finais do ensino fundamental e do ensino médio" (SANTA CATARINA, 2009a, p. 7) 
Por isso, investigar a formação e o trabalho docente com atenção a outros aspectos nos quais estão enredados, tais como os ideológicos, políticos, sociais, econômicos, culturais, entre outros, é fundamental para se aproximar de uma visão menos ingênua e mais crítica, que compreenda os processos formativos e o trabalho do professor como partes de um todo maior. Sob essa perspectiva, entende-se que conhecer mais sobre o processo de escolarização e as condições objetivas concretas que o constituem é um esforço constante a ser empreendido pelos envolvidos no processo de escolarização dos estudantes público-alvo do SAEDE, bem como dos pesquisadores que se propõe a estudar temáticas relativas à Educação Especial, uma vez que, conforme explicou Souza (2008), é este processo de escolarização que possibilita ou não que a escola possa cumprir sua finalidade social de escolarizar a todos.

\section{Considerações finais}

Este artigo procurou discutir como se caracteriza o trabalho e a formação do professor do SAEDE nas escolas da Rede Estadual de Ensino no município de Joinville, em Santa Catarina. Os aspectos do trabalho e da formação docente no SAEDE que foram abordados no âmbito deste artigo contemplaram a formação inicial e continuada das professoras, bem como os principais desafios do trabalho docente no Serviço de Atendimento Educacional Especializado, de acordo com a compreensão das professoras.

Foi possível evidenciar que a maneira como as professoras compreendem seu trabalho e os principais desafios deste no SAEDE pode ser reveladora de suas concepções sobre este serviço, sua função e sua relação com os demais envolvidos no processo de escolarização. Em suas falas, o trabalho docente no SAEDE aparece focado nos estudantes público-alvo da Educação Especial, porém chamou à atenção o fato de terem usado termos como "autonomia" e "empoderamento" ao se referirem a seu trabalho junto a esses alunos, e não "aprendizagem" ou "escolarização". Elas também citaram como parte de seu trabalho a adaptação de conteúdos e a orientação a pais e professores, mas ao relatarem seus principais desafios na realização da docência no SAEDE, foi recorrente a alusão à necessidade de obter conhecimento especializado em deficiências e transtornos, demonstrando que, nos espaços escolares em que atuam, parece vigorar uma perspectiva médico-psicológica dos processos de escolarização.

Essa perspectiva que parece habitar as escolas pesquisadas interage com outras compreensões, formando o que Libâneo, Oliveira e Toschi (2011) chamaram de traços culturais próprios da escola, que vão sendo internalizados pelas pessoas e geram um estilo coletivo de perceber o que se passa na escola. Nesse sentido, compreender aspectos do 
trabalho, bem como da formação docente, pela voz das professoras do SAEDE, consiste em uma forma de se aproximar de suas concepções que, em parte, orientam suas práticas pedagógicas, contribuindo ou não para o processo de escolarização dos alunos público-alvo da Educação Especial.

Reconheceu-se que a formação continuada, de fato, pode criar condições para que o trabalho docente no SAEDE se desenvolva com subsídios teóricos, planejamento e constante revisitação da própria prática, assim como a troca de experiências entre as professoras parece ter sido um caminho encontrado por elas na busca por uma aprendizagem contínua da docência.

No entanto, do mesmo modo que a formação permanente foi reconhecida como uma estratégia importante para o desenvolvimento profissional docente e o trabalho realizado junto aos estudantes público-alvo da Educação Especial, atentou-se para o fato de que ela não se configure como panaceia, isto é, uma espécie de solução para todos os desafios encontrados no trabalho docente.

Para isso, contudo, é necessário que sejam criadas condições de trabalho que possibilitem a existência desses momentos de discussão, sejam individuais ou coletivos. No município já há um dia por semana dedicado a planejamentos e formações para as professoras do SAEDE, em que são suspensos os atendimentos aos estudantes. Ainda assim, percebeu-se um processo de intensificação do trabalho docente no SAEDE nos outros quatro dias da semana, que são quase inteiramente focados em atendimentos, indicando que parece haver uma clara delimitação entre "hora de trabalhar" e "hora de planejar/estudar", como se tais atividades não estivessem imbricadas.

As constatações que puderam ser realizadas neste artigo possibilitam inferir que o trabalho e a formação de professores atuantes no SAEDE são aspectos que demandam contínua investigação, considerando quão recente é este serviço e atentando ao fato de que o modo como as docentes concebem seu trabalho e as condições em que este acontece têm estreita relação com o processo de escolarização do estudantes público-alvo da Educação Especial. Sugere-se, portanto, que no campo de estudos sobre o trabalho e a formação docente, bem como no âmbito das investigações científicas em Educação Especial, essa temática possa compor as pesquisas porvir.

Do mesmo modo, considera-se oportuno que os estudos já realizados sejam partilhados e discutidos junto aos professores do SAEDE e demais envolvidos no processo de escolarização dos estudantes público-alvo da Educação Especial, de modo a aproximar do cotidiano da escola análises que podem contribuir para a reflexão e o trabalho dos 
profissionais da Educação. Isto porque colocar esses saberes em ação pode ser uma forma de desenvolver uma concepção crítica sobre o seu trabalho.

\title{
ASPECTS OF TEACHER'S WORK AND EDUCATION IN SPECIALIZED EDUCATIONAL SERVICE OF SANTA CATARINA'S STATE SCHOOLS
}

\begin{abstract}
This paper aims to know aspects of the work and education of teachers working at Specialized Education Service (SAEDE) in state schools of Joinville/SC. The methodological procedures involved the application of questionnaires to sixteen teachers working in SEAS in state schools of Joinville, and their answers were analyzed through Content Analysis (FRANCO, 2012). Results showed that in-service education doesn't seem to be supported in the school context, due to the teachers' current working conditions, which are almost entirely dedicated to attend studentes. It was understood that, in order to comprehend aspects of SAEDE's teachers work and formation, it's necessary to know and discuss the school's organizational structure, as well as and the political, ideological and economic context that surround them and act as their determinants.
\end{abstract}

Keywords: specialized educational attendance; teacher's work; specialized educational service's teacher.

\section{ASPECTOS DEL TRABAJO Y FORMACIÓN DE PROFESORES EN SERVICIO EDUCATIVO ESPECIALIZADO EM ESCUELAS PÚBLICAS DEL ESTADO DE SANTA CATARINA}

\section{Resumen}

Este trabajo tiene como objetivo conocer los aspectos del trabajo y formación de profesores que trabajan en el Servicio Educativo Especializado (SAEDE) en escuelas públicas del estado de Santa Catarina en Joinville/SC. Los procedimientos metodológicos incluyeron el uso de cuestionarios a dieciséis maestros que trabajan en el SAEDE en Joinville, y sus respuestas fueron analizadas a través del análisis de contenido (FRANCO, 2012). Los resultados mostraron que la formación continuada formación en servicio no parece ser favorecida en los espacios de la escuela debido a las actuales condiciones de trabajo de los maestros, que están casi totalmente orientados a servir a los estudiantes. Se entendió que para comprender los aspectos del trabajo y formación de professores que trabajan em el SAEDE es necesario conocer y analizar la estructura organizativa de las escuelas, así como que el contexto político, ideológico y económico que rodea a estas escuelas y actúan como sus determinantes. Palabras clave: servicio educativo especializado; enseñanza; professor del servicio educativo especializado.

\section{Referências}

ARAÚJO, Bárbara Karolina. A formação do segundo professor de turma do estado de

Santa Catarina. 2015. 248 f. Dissertação de Mestrado. Universidade Federal de Santa Catarina, Florianópolis. 
ARROYO, Miguel González. Condição docente, trabalho e formação. In: SOUZA, João Valdir. (Org.). Formação de professores para a Educação Básica: 10 anos de LDB. Belo Horizonte: Autêntica, 2007, p.191-209.

BERNARDES, Cleide Aparecida Hoffmann. O trabalho docente no Atendimento Educacional Especializado pelas vozes de professoras especializadas. 2014. $179 \mathrm{f}$. Dissertação de Mestrado. Universidade da Região de Joinville, Joinville.

BRASIL. Ministério da Educação (MEC). Conselho Nacional de Educação (CNE). Câmara de Educação Básica (CEB). Resolução CNE/CEB n⿳ 4, de 2 de outubro de 2009. Institui Diretrizes Operacionais para o Atendimento Educacional Especializado na Educação Básica, modalidade Educação Especial. Brasília, DF: MEC/CNE, 2009.

. Ministério da Educação (MEC). Secretaria de Educação Continuada, Alfabetização e Diversidade (SECADI). Política Nacional de Educação Especial na Perspectiva da Educação Inclusiva. Brasília: MEC, 2008.

FRANCO, Maria Laura Puglisi Barbosa. Análise de conteúdo. 4.ed. Brasília: Liber Livro, 2012.

FREIRE, Paulo. Pedagogia da autonomia: saberes necessários à prática educativa. 47. ed. Rio de Janeiro: Paz e Terra, 2013.

FRIGOTTO, Gaudêncio. A dupla face do trabalho: criação e destruição da vida. In: FRIGOTTO, Gaudêncio; CIAVATTA, Maria. (Orgs.). A experiência do trabalho e a educação básica. 2. ed. Rio de Janeiro: DP\&A, 2005, p. 11-27.

GARCIA, Maria Manuela Alves; HYPOLITO, Álvaro Moreira; VIEIRA, Jarbas Santos. As identidades docentes como fabricação da docência. Educação e Pesquisa, São Paulo, v. 31, n. 1, p. 45-56, jan./abr. 2005.

GATTI, Bernadete Angelina; ANDRÉ, Marli Eliza D. A. de. A relevância dos métodos de pesquisa qualitativa em educação no Brasil. In: WELLER, Wivian; PFAFF, Nicolle. (Orgs.). Metodologias da pesquisa qualitativa em educação: teoria e prática. Petrópolis, RJ: Vozes, 2011, p. 29-38.

HADDAD, Cristhyane Ramos; SILVA, Daniel Vieira da. A hora atividade como processo de formação continuada. Trabalho apresentado na IX ANPEd Sul, GT 08 - Formação de Professores. Caxias do Sul/RS: 29 de julho a $1^{\circ}$ de agosto de 2012. Disponível em: <http://www.portalanpedsul.com.br/admin/uploads/2012/Formacao_de_Professores/Trabalho/ 05_05_38_641-7170-1-PB_apartir_deste.pdf >. Acesso em: 29 jan. 2017.

HYPOLITO, Álvaro Moreira; VIEIRA, Jarbas Santos; PIZZI, Laura Cristina Vieira. Reestruturação curricular e auto-intensificação do trabalho docente. Currículo sem Fronteiras, v.9, n.2, p.100-112, jul./dez. 2009.

LIBÂNEO, José Carlos; OLIVEIRA, João Ferreira de; TOSCHI, Mirza Seabra. (Orgs.). Educação escolar: políticas, estrutura e organização. 10. ed. São Paulo: Cortez, 2011. 
MARTINS, José de Souza. Exclusão social e a nova desigualdade. São Paulo: Paulus, 1997.

MICHELS, Maria Helena. Paradoxo da formação docente na política de educação inclusiva do Estado de Santa Catarina: a perspectiva clínica como sustentação do trabalho escolar. In: BAPTISTA, Claudio Roberto e JESUS, Denise Meyrelles de. (Org.). Avanços em políticas de inclusão: o contexto da educação especial no Brasil e em outros países. 3.ed. Proto Alegre: Mediação, 2015.

A formação de professores de educação especial na UFSC (1998-2001):

ambigüidades estruturais e a reiteração do modelo médico-psicológico. Tese de Doutorado. 2004. 169 f. Pontifícia Universidade Católica de São Paulo, São Paulo.

OLIVEIRA, Dalila Andrade. Trabalho docente. In: ; DUARTE, A.M.C.; VIEIRA, L.M.F. DICIONÁRIO: trabalho, profissão e condição docente. Belo Horizonte: UFMG/Faculdade de Educação, 2010. CD-ROM.

RENGEL, Juliana Testoni dos Santos; CORDEIRO, Aliciene Fusca Machado; STEINER, Daiana Rabock. Identidade docente e inclusão escolar: um estudo sobre a produção acadêmica brasileira (2008-2014). In: Congresso Nacional de Educação - EDUCERE, 12. Curitiba, 2015. Disponível em:

<http://educere.bruc.com.br/arquivo/pdf2015/17734_7690.pdf>. Acesso em: 29 jan. 2016.

ROLDÃO, Maria do Céu. Que é ser professor hoje? A profissionalidade docente revisitada. Revista da ESES, 1, nova série, p. 79-87, 1998.

SANTA CATARINA (Estado). Secretaria de Estado da Educação. Fundação Catarinense de Educação Especial. Programa Pedagógico. São José, SC: FCEE, 2009a.

Secretaria de Estado da Educação. Fundação Catarinense de Educação Especial.

Política de Educação Especial do Estado de Santa Catarina. Coordenador: Sergio Otavio Bassetti. São José, SC: FCEE, 2006.

Lei complementar $n^{\circ}$ 456, de 11 de agosto de 2009. Disciplina a admissão de pessoal por prazo determinado no âmbito do Magistério Público Estadual, para atender a necessidade temporária de excepcional interesse público, sob regime administrativo especial, nos termos do inciso IX do art. 37 da Constituição Federal. Florianópolis: 2009b. Disponível em: <http://server03.pge.sc.gov.br/LegislacaoEstadual/2010/000456-010-0-2010-001.htm>. Acesso em: 04 abr. 2017.

SANTOS, Juliana Testoni dos. Professoras atuantes no Atendimento Educacional Especializado e suas histórias de vida: um estudo sobre identidade docente. Dissertação de Mestrado. 2016. 112 f. Universidade da Região de Joinville, Joinville.

SAWAIA, Bader. Introdução: exclusão ou inclusão perversa? In: As artimanhas da exclusão: análise psicossocial e ética da desigualdade social. Petrópolis, RJ: Vozes, 2012.

SILVEIRA, Denise Tolfo. CÓRDOVA, Fernanda Peixoto. A pesquisa científica. In: GERHARDT, Tâtiana Engel; SILVEIRA, Denise Tolfo. (Orgs.). Métodos de pesquisa. Porto Alegre: Editora da UFRGS, 2009, p. 31-42. 
SOUZA, Marilene Proença Rebello de. Retornando à patologia para justificar a não aprendizagem escolar: a medicalização e o diagnóstico de transtornos de aprendizagem em tempos de liberalismo. Trabalho apresentado na sessão especial "Medicalização na educação infantil e no ensino fundamental e as políticas de formação docente". In: Reunião Nacional da ANPEd, 31. Caxambu, 2008. Disponível em: $<$ http://31reuniao.anped.org.br/4sessao_especial/se\%20-\%2012\%20-

$\% 20$ marilene $\% 20$ proena $\% 20$ rebello\%20de\%20souza\%20-\%20participante.pdf $>$. Acesso em: 28 mar. 2017.

TAMBARA, Elomar. Profissionalização, escola normal e feminilização: magistério sul-riograndense de instrução pública no século XIX. História da Educação, Pelotas: ASPHE /FaE/UFPel, n.3, pp.35-58, abr. 1998.

TARDIF, Maurice. Saberes docente e formação profissional. 17.ed. Petrópolis, RJ: Vozes, 2014.

Data de recebimento: $28 / 04 / 2017$

Data de aceite: $11 / 10 / 2017$

\section{Sobre as autoras:}

Lediane Coutinho é mestranda em Educação pela Universidade da Região de Joinville. Possui graduação em Pedagogia pela mesma universidade (2001). Atualmente é tutor externo da Faculdade do Grupo UNIASSELVI e professora (ensino fundamental) do Instituto Superior e Centro Educacional Luterano Bom Jesus. Participa do Grupo de Estudos e Pesquisas sobre o Trabalho e a Formação Docente (GETRAFOR). Tem experiência na área de Educação, com ênfase em Educação. Endereço Eletrônico: ledicoutinho@gmail.com

Aliciene Fusca Machado Cordeiro possui graduação em Psicologia pela Pontifícia Universidade Católica de Campinas (1995), mestrado em Educação (Psicologia da Educação) pela Pontifícia Universidade Católica de São Paulo (2001) e doutorado em Educação (Psicologia da Educação) pela Pontifícia Universidade Católica de São Paulo (2006). É professora-pesquisadora da Universidade da Região de Joinville - UNIVILLE. Tem experiência na área de Psicologia, com ênfase em Educação, atuando principalmente nos seguintes temas: educação inclusiva, educação especial, deficiência, educação, ensino e aprendizagem. Endereço Eletrônico: aliciene_machado@hotmail.com 